\title{
Implanon Discontinuation Rate and It's Associated Factors in Debre Tabor Town, North Central Ethiopia
}

\author{
Awoke Giletew Wondie \\ Department of Public Health, Debre Tabor University, Debre Tabor, Ethiopia \\ Email address: \\ awokegiletew@yahoo.com \\ To cite this article: \\ Awoke Giletew Wondie. Implanon Discontinuation Rate and It's Associated Factors in Debre Tabor Town, North Central Ethiopia. Science \\ Journal of Clinical Medicine. Vol. 8, No. 2, 2019, pp. 6-12. doi: 10.11648/j.sjcm.20190802.11
}

Received: April 24, 2019; Accepted: May 24, 2019; Published: June 13, 2019

\begin{abstract}
Family planning could avert a significant number of maternal mortality and contributes to child survival with its focus on women's rights. Generally, a long-acting reversible contraceptive is more effective and cover all the advantage and eliminates the disadvantages of other types of contraceptives. The acceptance and utilization of long-acting reversible contraceptive including implanon were very low in many developing countries including Ethiopia. The purpose of this study was to assess the level of discontinuation and to identify variables influencing Implanon utilization. A cross-sectional design was conducted between January to December 2018 in Debre Tabor town. In the community, a total of 132 women who have been using or discontinuing Implanon during the study period were selected. Face-to-face interviews using a structured questionnaire were conducted for data collection. The data were entered, cleaned and analyzed by a statistical package for social sciences version 20 . The data were processed and analyzed by a statistical package for social sciences version 20 using descriptive and analytical statistics including chi-square test that identified the association between some selected independent variables and implanon discontinuation. The overall implanon discontinuation in the year 2018 was $16.7 \%$ in Debre Tabor town. The most frequently mentioned reason for implanon discontinuation was health-related issues (31.8\%), side effects $(27.3 \%)$, desire to have more children $(22.7 \%)$ and method shift (18.2\%). Factors associated with Implanon discontinuation were developing side effects, women who have living children and not providing counseling service. Implanon discontinuation among Implanon users in Debre Tabor town during the year 2018 was found to be high and the most frequently mentioned rationale was health-related issues. Health care providers should provide counseling before Implanon insertion.
\end{abstract}

Keywords: Implanon, Discontinuation, Ethiopia

\section{Introduction}

In 2015, there were an estimated 275,288 maternal deaths in 2015, yielding an MMR of 210 maternal deaths per 100 000 live births and Sub-Saharan Africa region accounting for a greater proportion of the global maternal deaths [1]. Even though Ethiopia is progressing in terms of reducing underfive mortality, maternal mortality shows little or no changes in the last decades. This could be attributed to the high fertility rate due to inadequate family planning service quality and accessibility that exacerbated the burden of maternal and child health [2-4].

In the less developed regions, $67 \%$ contraceptive prevalence rate is expected to achieve the desired level of fertility in the region by 2025 . However, in sub- Saharan African countries evidence reported a high level of unmet need $(26.8 \%)$ and fertility level (5.3 children per women) $[3,5,6]$.

In Ethiopia, $6 \%$ of married or in-union women of reproductive age in 2000 were using modern contraception which reached $35 \%$ in 2016 . The method specifically, $3 \%$ of women in 2000 relied on injectables that increased to $23 \%$ in 2016 followed by implanon utilization from less than $1 \%$ of women using in 2000 to $8 \%$ in 2016. However, in 2016, 22\% of married or in-union women are estimated to have had an unmet need for family planning and a high fertility rate of 4.6 children per woman [7].

Furthermore $35 \%$ of modern contraceptive users discontinued before 12 months of contraceptive use by wishing to become pregnant $(42 \%)$ and health-related issues $(18 \%)$. This was consistent with a reported 520 number of implants use discontinuation due to the major reason of wanting to become pregnant $(42.1 \%)$, health concerns/side 
effects $(24.1 \%)$ and wanting a more effective method $(10.8 \%)$ [7].

Ethiopia has registered an increasing trend in contraceptive prevalence rate in the last decade and the contribution of the Health Extension Program in expanding access to family planning is clearly evident. However, the national contraceptive prevalence rate is still low. This could be attributable to inadequate provision of modern contraceptive and a limitation in providing a comprehensive FP service [810]. Although evidence was generated on modern contraceptives including implants, however, it was limited regarding the discontinuation of Implanon in the study area. Hence the objectives of this study were to assess the level of discontinuation and variables influencing Implanon discontinuation among Implanon users in the year 2018 in Debre Tabor town.

\section{Material and Methods}

\subsection{Study Area}

This study was conducted in Debre Tabor town which is the capital of South Gondar Zone and 666Km North Central of Addis Ababa. Based on the information from Debre Tabor town Administrative Bureau the town has four kebeles and a total population of 87,627 , among them about 14,462 women were under the age of reproduction who is the target group for contraceptive use. In the town Implanon insertion and removal service was provided by zonal hospital (1), primary health care centers (3) and health posts (4) during the study period. There were a total of 1474 users of long-acting family planning methods in all health institution of the town in 2018 G. C. among them 314 were Implanon users.

\subsection{Study Design and Period}

The community-based cross-sectional study design was conducted among Implanon users' and discontinuers' between January 01 and December 30, 2018, in Debre Tabor town.

\subsection{Sample Size and Sampling Procedure}

The sample size was determined using a single population proportion formula by taking a discontinuation rate of $16 \%$ Implanon in Ofla Woreda in Tigray region [9]. However, the numbers of women who are using Implanon in January 2018 in Debre Tabor town in all health institutions were 314 women. Due to a small number of total populations in the study area, the reduction formula makes sample size 124 and by assuming a response rate of $90 \%$, the final sample size becomes 136. Simple random sampling technique was used to select the study participants.

\subsection{Data Collection}

Pretested and structured questionnaires using face-to-face interviews were used for data collection. The questionnaire was first developed in English language and then translated into Amharic (the local language), and back into English. The questionnaire was developed by adapting items from previous studies. The component of the questionnaire includes socio-demographic, contraception history, and the use of Implanon. It was pre-tested among 5\% similar study population, based on which necessary improvement was made in clarifying vague terms. Each of the questions in the questionnaire was explained by translating into the local language for study participants to enable them to have the understanding and to give a proper response to the questions that were asked. Data were collected by two trained data collectors who were supervised by the principal investigator. Every day, questionnaires were reviewed and checked for completeness of data collection by principal investigator and inconsistencies and errors on skip pattern were corrected accordingly.

\subsection{Data Analysis}

Processed data were analyzed using descriptive statistics of frequency and percentage. Summary statistics were used to describe the study population in relation to the relevant variables and inferential statistics of chi-square test was done using a statistical package for social sciences version 20. A probability value of less than 0.05 was used to declare statistical significance.

\subsection{Operational Definition}

For this study, discontinuation of Implanon would refer to the removal of Implanon earlier than the prescribed time that is using for less than 2.5 years.

\section{Results}

In this study, a total of one hundred thirty-two (132) individuals provide a complete response and included in the analysis with a response rate of $100 \%$.

\subsection{Socio-Demographic Characteristics}

Table 1 shows the sociodemographic profile of the study participants. The minimum respondents' age observed was 16 year and the maximum was 45 years, among whom more than one third $46(34.8 \%)$ were between $25-29$ years of age. One hundred sixteen $(88 \%)$ of the participants were married and majority $121(91.7 \%)$ of study participants were Orthodox Christians in religion. More than half (59.1\%) participants were merchants by occupation followed by housewives who accounted for $37(28.1 \%)$. The monthly income of more than two fifths $(46.2 \%)$ of respondents were less than one thousand Ethiopian birrs.

Table 1. Socio-demographic status of respondents in Debre Tabor town, North Central Ethiopia, $2018(n=132)$.

\begin{tabular}{llll}
\hline Variables & & Frequency & Percent \\
\hline \multirow{3}{*}{ Age } & $<20$ & 9 & 6.8 \\
& $20-24$ & 27 & 20.5 \\
& $25-29$ & 46 & 34.8 \\
\hline
\end{tabular}




\begin{tabular}{|c|c|c|c|}
\hline Variables & & Frequency & Percent \\
\hline \multirow{6}{*}{ Marital status } & $30-34$ & 28 & 21.2 \\
\hline & 35 and more & 22 & 16.7 \\
\hline & Married & 116 & 88.0 \\
\hline & Divorced & 7 & 5.3 \\
\hline & Single & 6 & 4.5 \\
\hline & Widowed & 3 & 2.2 \\
\hline \multirow{3}{*}{ Religion } & Orthodox & 121 & 91.7 \\
\hline & Muslim & 8 & 6.1 \\
\hline & Protestant & 3 & 2.2 \\
\hline \multirow{4}{*}{$\begin{array}{l}\text { Women's } \\
\text { Educational status }\end{array}$} & Illiterate & 47 & 35.6 \\
\hline & Grade 1-8 & 70 & 53.0 \\
\hline & Grade 9-12 & 8 & 6.1 \\
\hline & College and above & 7 & 5.3 \\
\hline \multirow{4}{*}{$\begin{array}{l}\text { Husband's } \\
\text { Educational } \\
\text { status (n=116) }\end{array}$} & Illiterate & 38 & 32.8 \\
\hline & Grade 1-8 & 59 & 50.8 \\
\hline & Grade 9-12 & 14 & 12.1 \\
\hline & College and above & 5 & 4.3 \\
\hline \multirow{4}{*}{$\begin{array}{l}\text { Women's } \\
\text { occupational status }\end{array}$} & Merchant & 78 & 59.1 \\
\hline & Housewife & 37 & 28.1 \\
\hline & Gov.t/private employee & 13 & 9.8 \\
\hline & Other & 4 & 3.0 \\
\hline \multirow{3}{*}{$\begin{array}{l}\text { Monthly } \\
\text { income(ETB) }\end{array}$} & $<1000$ & 61 & 46.2 \\
\hline & $1000-3000$ & 55 & 41.7 \\
\hline & $>3000$ & 16 & 12.1 \\
\hline
\end{tabular}

\subsection{Gynecologic History of Respondents}

Among all respondent 111(84.1\%) were having at least one living child among whom $79(71.2 \%)$ women had two to four living children. Out of all respondents majority $(81.8 \%)$ were intended to have a child or more children in the future; from which almost two in five $(39.8 \%)$ of respondents were intended to have three or more children. There were $7(5.3 \%)$ women who had at least one history of abortion among whom five $(71.4 \%)$ abortion were practiced once and the remaining $2(28.6 \%)$ encountered two episodes of abortion (Table 2).
Table 2. Gynecologic history of respondents in Debre Tabor town, North Central Ethiopia, 2018.

\begin{tabular}{llll}
\hline Variables & & Frequency(132) & Percent (\%) \\
\hline \multirow{2}{*}{ Have children(n=132) } & Yes & 111 & 84.1 \\
& No & 21 & 15.9 \\
Number of children & 1 & 24 & 21.6 \\
(n=111) & $2-4$ & 79 & 71.2 \\
& 5 and more & 8 & 7.2 \\
Intend to have /more & Yes & 108 & 81.8 \\
children(n=132) & No & 24 & 18.2 \\
Number of children & One & 28 & 25.9 \\
intended to have & Two & 37 & 34.3 \\
(n=108) & Three and more & 43 & 39.8 \\
History of abortion & Yes & 7 & 5.3 \\
$(\mathrm{n}=132)$ & No & 125 & 94.7 \\
& One & 5 & 71.4 \\
Number of abortion & Two & 2 & 28.6 \\
$(\mathrm{n}=7)$ & Three and more & 0 & 0 \\
\hline
\end{tabular}

Seventy-two (54.5\%) respondents' had a history of only implanon use, they have no previous experience of contraceptive utilization other than Implanon. The rest 60 (45.5\%) had used modern methods of contraceptives before Implanon insertion. Injectables, pills and other methods of modern contraceptive (IUCD and Implanon) were used by the women which account for $34(56.7 \%), 24(40 \%)$ and 2 $(3.3 \%)$ respectively. Majority $(43.1 \%)$ of respondents were not used any contraceptive before Implanon insertion because of the fear of side effects and also not in relationship/no sexual partner, the need to get pregnant and to have child, and husband's disapproval were the other reasons not to use any contraceptives before Implanon use which accounts for $17(23.6 \%), 14(19.4 \%)$ and $10(13.9 \%)$ respectively (Table 3 ).

Table 3. History of contraceptive use by respondents in Debre Tabor town, North Central Ethiopia, 2018.

\begin{tabular}{llll}
\hline Variables & & Frequency & Percent \\
\hline Heard of other contraceptive methods $(\mathrm{n}=132)$ & Ever heard & 132 & 100 \\
& Never heard & 0 & 0 \\
& Health personnel & 104 & 78.8 \\
Source where they heard contraceptive methods $(\mathrm{n}=132) *$ & Mass media & 81 & 61.4 \\
& Friends/relatives & 37 & 28.0 \\
& Others & 8 & 6.1 \\
Type of information they know about contraception methods & Benefit & Duration of action & 69.7 \\
(n=132) & Side effects & 73 & 55.3 \\
& Effectiveness & 41 & 31.1 \\
History of other contraceptive utilization other than Implanon & Yes & 22 & 16.7 \\
(n=132) & No & 60 & 45.5 \\
& Injectables & 72 & 54.5 \\
The last method used before current Implanon & Pills & 34 & 56.7 \\
insertion(n=60) & Others & 24 & 40.0 \\
& Fear of side effect & 2 & 3.3 \\
Reason for not using any contraceptive before Implanon use & Not in relationship & 31 & 43.1 \\
(n=72) & Need to get pregnant / have a child & 17 \\
& Husband disapproval & 14 & 23.6 \\
\hline
\end{tabular}




\subsection{Rate of Implanon Discontinuation}

Of all respondents who used Implanon in the year 2018, 82 $(62.1 \%)$ continues using Implanon. The remaining 50 (37.9\%) participants removed the implant during the study period. Among 50 (37.9\%) who removed implanon, about $22(44 \%)$ discontinue before 2.5 years and the rest $28(56 \%)$ discontinue after 2.5 years or more duration of implanon use (Figure 1). This makes the overall early Implanon discontinuation rate of $16.7 \%$. The most frequently stated reason for discontinuation of implanon use was side effects, wishing to have children and the need to shift to other methods (Figure 2).

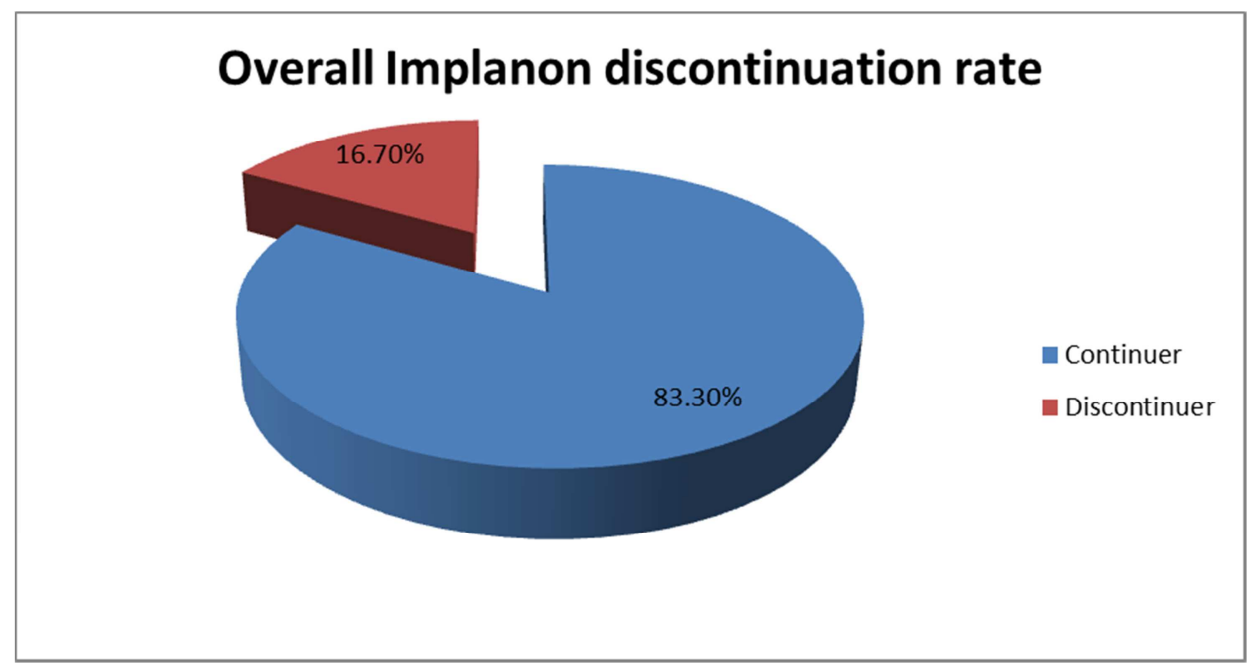

Figure 1. The overall discontinuation rate of implanon among Implanon users in 2018 in Debre Tabor town, North Central Ethiopia, 2018

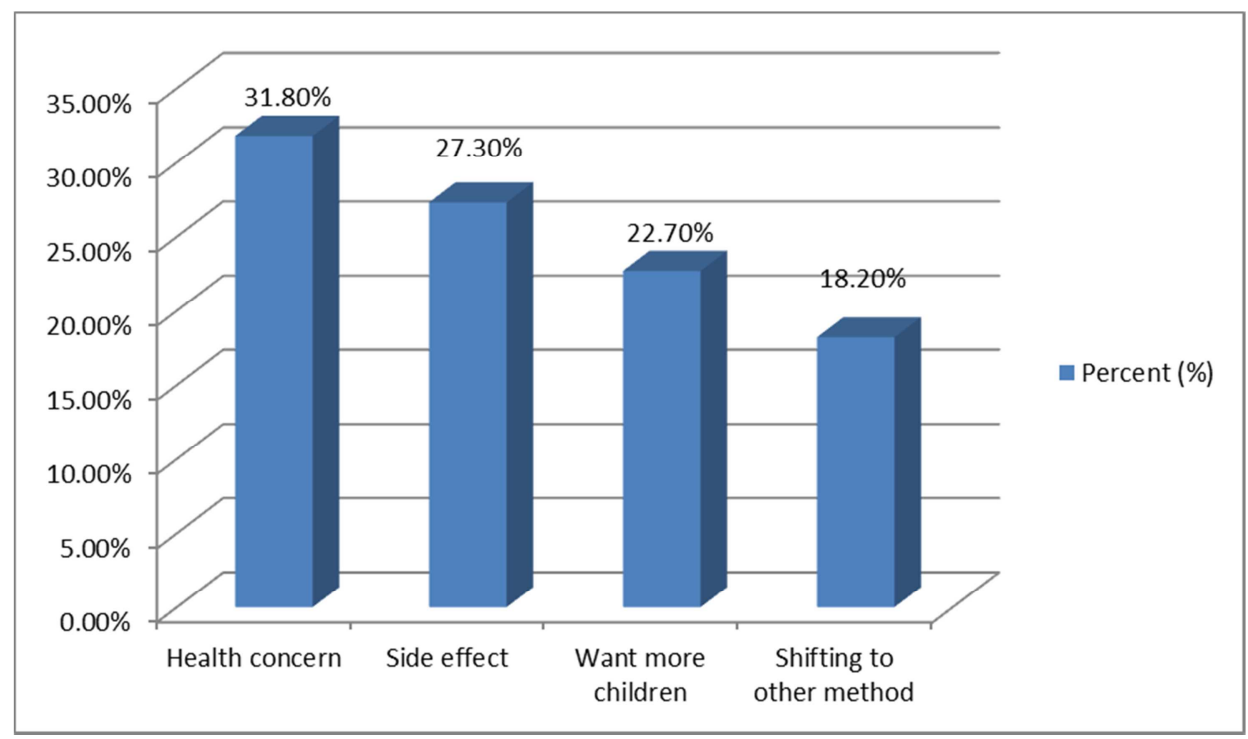

Figure 2. Reasons for implanon removal in the year 2018 in Debre Tabor town, North Central Ethiopia, 2018.

One hundred twelve $(84.8 \%)$ respondents counseled at the time of implanon insertion, among whom 91(81.3\%) counseled individually, $6(5.6 \%)$ in mass and $15(13.4 \%)$ with their husband. Among those who got counseling service during insertion, 94 (83.9\%) were counseled about Implanon benefit, $81(72.3 \%)$ about its side effects, 52 (46.4\%) about its effectiveness and $28(25 \%)$ were also counseled about its duration of action that lasts for less than 15 minutes in three fourths of counseling's and for 15 minutes or above in one quarter of participant's counseling. Eighty-three (71.5\%) of women among the married were discussed with their husbands before inserting Implanon and most (94\%) of them got their husband's approval for Implanon insertion. However, the remaining 5(6\%) were inserted Implanon without their husband's approval. In nearly three-fifths (59.1\%) of participants both the husband and the woman herself were decided to insert Implanon and in the remaining $51(38.6 \%)$ and $3(2.3 \%)$ Implanon insertion was decided by the woman only and by her friends or relatives respectively even those who have husband were not involved their husband in decision making to insert Implanon (Table 4). 
Table 4. Characteristics of respondents related to implanon use in Debre Tabor town, North Central Ethiopia, 2018.

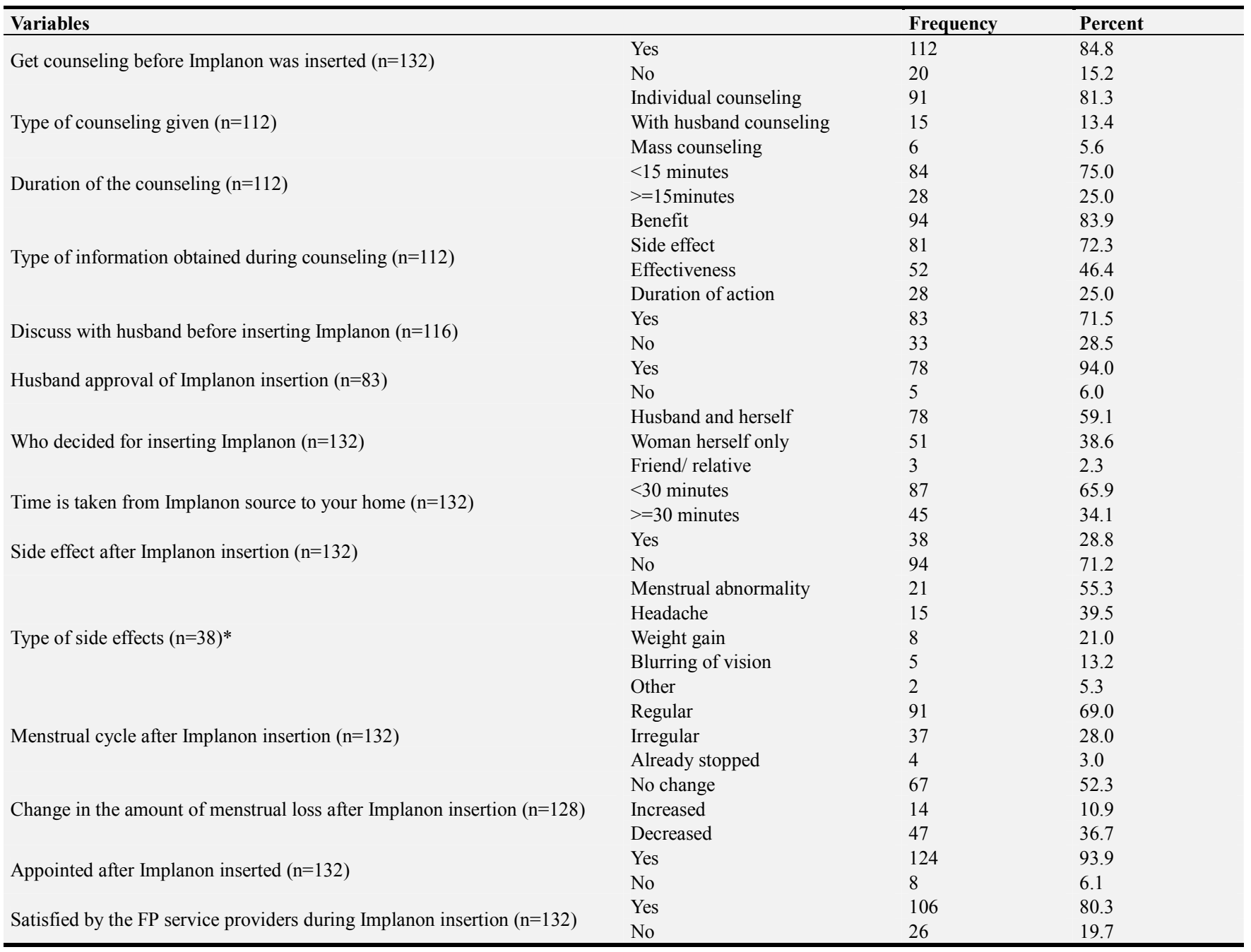

\subsection{Factors Associated with Implanon Discontinuation}

The influence of selected sociodemographic and other variables on the outcome variable was checked using the chi-square test. Hence, the presence of living children got counseling service, the presence of side effects and presence of menstrual abnormality were significantly associated ( $\mathrm{p}$-value $<0.05$ ) with discontinuation of Implanon in the chi-square test (Table 5).

Table 5. Factors associated with Implanon discontinuation among 2018 Implanon users in Debre Tabor town, North Central Ethiopia, 2018

\begin{tabular}{|c|c|c|c|c|c|c|}
\hline \multirow{2}{*}{ Variables } & & \multicolumn{5}{|c|}{ Continuation of Implanon } \\
\hline & & Yes & No & $\mathbf{X}^{2} *$ & Df** & P-value \\
\hline \multirow{2}{*}{ Living children } & Yes & 102 & 9 & \multirow{2}{*}{$X^{2}=36.8$} & \multirow{2}{*}{$\mathrm{Df}=1$} & \multirow{2}{*}{0.000} \\
\hline & No & 8 & 13 & & & \\
\hline \multirow{2}{*}{ Counseling has given } & Yes & 107 & 5 & \multirow{2}{*}{$X^{2}=79.2$} & \multirow{2}{*}{$\mathrm{Df}=2$} & \multirow{2}{*}{0.000} \\
\hline & No & 3 & 17 & & & \\
\hline \multirow{2}{*}{ Presence of side effects } & Yes & 23 & 15 & \multirow{2}{*}{$X^{2}=20$} & \multirow{2}{*}{$\mathrm{Df}=1$} & \multirow{2}{*}{0.000} \\
\hline & No & 87 & 7 & & & \\
\hline \multirow{2}{*}{ Menstrual abnormality } & Yes & 10 & 11 & \multirow{2}{*}{$X^{2}=22.9$} & \multirow{2}{*}{$\mathrm{Df}=2$} & \multirow{2}{*}{0.000} \\
\hline & No & 100 & 11 & & & \\
\hline \multirow{2}{*}{ Satisfaction with the service } & Yes & 93 & 13 & \multirow{2}{*}{$\mathrm{X}^{2}=7.51$} & \multirow{2}{*}{$\mathrm{Df}=3$} & \multirow{2}{*}{0.06} \\
\hline & No & 17 & 9 & & & \\
\hline
\end{tabular}

$*$ Chi-square, $* *$ Degree of freedom p-value $<0.05$-significant association

\section{Discussion}

The objectives of this study were to assess the level of discontinuation and variables influencing Implanon discontinuation in Debre Tabor town among women Implanon users and discontinuers' during 2018. From the findings of this study, Implanon discontinuation among women was $16.7 \%$ in Debre Tabor town. However, studies 
conducted in Nigeria, Malaysia, and Thailand reported a lower level of discontinuation than a result reported by this study [11-15]. This could be due to a discrepancy in sociodemographic profile or due to a difference in methods employed, the current study was done by cross-sectional study design in a community setting. However, other studies were institutional and follow-up studies. On the contrary, the level of Implanon discontinuation was lower than a study done in the United Kingdom. This could be due to a difference in the source population. Hence this study was done in urban residents; however, the latter study was done in both rural and urban residents [16]. It might be explained by the discrepancy in the educational status of respondents in the later study where a major proportion of study participants were educated than the present study.

In this study, the most frequent reason for Implanon discontinuation was health-related issues $(31.8 \%)$ followed by developing side effects $(27.3 \%)$ which was higher than the national level reason stated as a health concerns/side effects $(24.1 \%)$. This was followed by another reason for Implanon discontinuation stated as a desire to have more children $(22.7 \%)$ which was lower than the national level mentioned as a reason of a desire to become pregnant (42.1\%). Additionally, in this study method shift accounted for $18.2 \%$ of study participants' reason for Implanon discontinuation, however, this was relatively higher than 2016 EDHS survey that reported wanting a more effective method $(10.8 \%)$ for Implanon discontinuation [7]. This could be due to the number of samples considered in this study was much lower than a national survey. However, the level of all the abovementioned reasons for Implanon discontinuation reported by this study was similar to other studies [7, 12, 15, 17, 18].

Among all Implanon discontinuers', the proportion was higher among respondents who were not counseled [17]. Desire to have more children, side effects, need to shift to other method and health concerns were the reasons of women not to continue Implanon in future until 3 years of its insertion. Husband opposition was among the reasons for not to using family planning which was similar to a study conducted in Niger. This indicates the need to involve partners in the counseling service provision [19].

In this study, the presence of living children got counseling service, the presence of side effects and the presence of menstrual abnormality was identified associated factors with Implanon discontinuation. The women having living children have an association with the discontinuation of Implanon. Study participants who reported a complaint of side effect during Implanon utilization have a higher chance of implanon discontinuation which was consistent with another study in Egypt [13]. It might be explained by the quality of counseling service or the minimal users' tolerance for the side effect of Implanon. Those who got counseling service at the time of insertion had a lower chance of Implanon discontinuation as compared to those who were not counseled which could be the provision of better counseling service given to the women and may this result in the women not worry on minor side effects developed following
Implanon use and not remove Implanon early.

\section{Conclusion}

The level of discontinuation was founded to be high among implanon users in the year 2018. The most frequently mentioned justification for discontinuation of implanon was health-related issues, wishing to have children, developing side effects and a desire of method shifting. Developing side effects including menstrual abnormality during using of implanon, having living children and absence of counseling during insertion were factors influencing discontinuation of implanon.

Therefore, the government, health service providers and all stakeholders should work in collaboration to decrease early implanon discontinuation rate. Appropriate counseling service should be offered.

\section{Acknowledgements}

The author thanks the health care service providers in Debre Tabor town.

\section{Conflict of Interest}

All the authors do not have any possible conflicts of interest.

\section{References}

[1] Kassebaum NJ, Bertozzi-Villa A, Coggeshall MS, Shackelford KA, Steiner C, Heuton KR, Gonzalez-Medina D, Barber R, Huynh C, Dicker D, et al: Global, regional, and national levels and causes of maternal mortality during 1990-2013: a systematic analysis for the Global Burden of Disease Study 2015. Lancet. 2016;388(10053): 1775-812.

[2] Abouzahr C, Wardlaw T. Maternal Mortality in 2000: Estimates by WHO, UNICEF \& UNFPA: Department of Reproductive health Research World Health Organization, Geneva; $2004 \mathrm{Http} / /$ www. Who. In/whom estimates 2000. pdf.

[3] Awareness and determinants of family planning practice in Jimma, Ethiopia,

http://onlinelibrary.wiley.com/doi/10.1111/j.14667657.2006.00492.x/full

[4] BMC Public Health. Withdrawal users' experiences of and attitudes to contraceptive methods: a study from the Eastern district of Tehran, Iran, Rahnama; December 22, 2010; 10: 779 .

[5] Adeleye O. A. Akoria Z. O Shuaib and Ognoloh. O. D. Barriers and knowledge of Benefits Regarding Family planning method among women Attending Antenatal clinics in Southern Nigerian community. Asian Journal of medical sciences, 2010, 2(4): 190-194.

[6] Biruk T, Assefa H, Georges R. The prevalence of covert use of contraceptive in Nazareth, Adama town. Population studies and Research center, AAU of 2002. 
[7] Central Statistical Agency (CSA) [Ethiopia] and ICF. 2016. Ethiopia Demographic and Health Survey 2016. Addis Ababa, Ethiopia, and Rockville, Maryland, USA: CSA and ICF.

[8] David PH, Reichenbach L, Savelieva I, Vartapetova N, Potemkin. Women's reproductive health needs in Russia: what can we learn from an intervention to improve post-abortion care?. American Red Cross National Headquarters, 2025 E Street NW, Washington DC 2006, USA.

[9] Jamal A. Comparison of factors influences utilization of modern contraceptive methods among Rural and Urban women currently using Family Planning Service in South Wollo Zone Amhara National Regional State, 2010 A. A Ethiopia.

[10] Jane T. Bertrand, Karen H, Robert J. Access Quality of care and medical Barriers in family planning programs. International family planning perspectives, 21: 64-69 \&76, 1995, accessed at http://www.dictionary.com

[11] Sergent F, et al., Acceptability of the etonogestrel-containing contraceptive implant (Implanon).[French]. GynecolObstetBiolReprod, 2004. 33: p. 407-15.

[12] ChaovisitsareeSomsak, et al., One Year Study of Implanon on the Adverse Events and Discontinuation. J Med Assoc Thai 2005. 88(33 ): p. 314-317. MastorAsmah, Khaingsi Lay, and Omar sitiZawiah, Users' perspectives on Implanon in Malaysia, a multicultural Asian country. Open Access Journal of Contraception, 2011. 2: p. 79-84.
[13] MastorAsmah, Khaingsi Lay, and Omar sitiZawiah, Users' perspectives on Implanon in Malaysia, a multicultural Asian country. Open Access Journal of Contraception, 2011. 2: p. $79-84$

[14] Mutihir j. t and Nyangod. d., Indications for removal of etonogestrel implant within two years of use in Jos, Nigeria. East African Medical Journal November 2010. 87 p. 11

[15] Mutihir JT and Nyango DD, One-year experience with Implanon sub-dermal implants in Jos, Nigeria. Nigerian Journal of Clinical Practice, March 2010. 13(1): p. 28-31

[16] Lakha F and Glasier AF, Continuation rates of Implanon in the UK: data from an observational study in a clinical setting Contraception 2006. 74(4): p. 287-9.

[17] Mohamed Abdel-RazikMadiha Said, Implanon Use Pattern among Ministry of Health and Population Clients 2008-2012. December 2012, Faculty of Medicine, Cairo University: Cairo.

[18] Mutihir JT and Daru PH, Implanon sub-dermal implants: a 10month review of acceptability in Jos, North-Central Nigeria. Nigerian Journal of Clinical Practice, 2008. 11(4): p. 320-323.

[19] Affandi B, An integrated analysis of vaginal bleeding patterns in clinical trials of Implanon. Contraception, 1998. 58(6 Suppl): p. 99S-107S 